\title{
Leaving us with fond memories, smiles, SMILES and, alas, tears: a tribute to David Weininger, 1952-2016
}

\author{
Johann Gasteiger ${ }^{1} \cdot$ Yvonne Martin $^{2} \cdot$ Anthony Nicholls $^{3} \cdot$ Tudor I. Oprea $^{4} \cdot$ Terry Stouch $^{5}$
}

Received: 26 January 2018 / Accepted: 31 January 2018 / Published online: 3 February 2018

(c) Springer International Publishing AG, part of Springer Nature 2018

\begin{abstract}
David Weininger's career, accomplishments, genius, and friendship are warmly remembered by several of his colleagues, friends, and admirers.
\end{abstract}

\section{Introduction by the Editor}

\section{Terry Stouch}

Have you known anyone who landed one of their planes on a Los Angeles freeway? Or, do you know anyone who bought a Mount Palomar telescope, transported it 900 miles, and installed it in their backyard (after building an observatory, of course)? Maybe you know someone who set up a chemistry lab at home and developed a procedure to remove xanthine derivatives from chocolate so that allergic friends could enjoy a treat? How about someone who meets high level, coat-and-tie executives at major pharmaceutical companies while wearing jeans, sandals and a tee shirt and was still able to make big deals? Lived in a barge in New Orleans? Or, perhaps you know someone who in short order

Terry Stouch

tstouch@gmail.com

Johann Gasteiger

johann.gasteiger@fau.de

Yvonne Martin

yvonnecmartin@comcast.net

Anthony Nicholls

Anthony@ eyesopen.com

Tudor I. Oprea

toprea@salud.unm.edu

1 Computer-Chemie-Centrum, University of Erlangen-

Nuremberg, 91052 Erlangen, Germany

2 Martin Consulting, Waukegan, IL, USA

3 OpenEye Scientific Software, Santa Fe, NM, USA

4 The University of New Mexico, Albuquerque, NM, USA

5 Science For Solutions, LLC, West Windsor, NJ, USA turned a difficult technical task into a straightforward easyto-use approach that is now used worldwide and revolutionized the field of cheminformatics?

It's seldom we meet anyone who has done any one of these. But, if you know someone who has done all of them (and many more) then you knew David Weininger.

I had the honor of knowing Dave and having some great conversations with him. I was always struck by his thoughtfulness and insight. I never knew him to back away from a discussion or to be without thoughtful comments. Dave was full of ideas. The JCAMD community was deeply saddened by Dave's demise.

I consider myself to have been little more than an acquaintance; however, the recollections that follow come from four of his close friends and colleagues and tell at least portions of the story of Dave from four different angles. It's well worth your time to read them all-it's not often that someone like Dave comes along.

\section{So long, and thanks for all the SMILES}

\section{Tudor Oprea}

David WeiningerPhD, born 5-August-1952 in Brooklyn, NY, died 2-November-2016 in Santa Fe, NM. Dave is survived by his brothers Art and Yohanan (John) Weininger.

"It's as if we're in LA", said Dave in May 2000, as he was leaning against one of the steel atoms representing the cognition enhancer, 10-tons steel molecule that he had engineered and build, a sculpture in front of the Daylight Chemical Information Systems building outside Santa Fe, NM. "On a clear day, you could see as far as the Humphreys peak", he mused. The $3811 \mathrm{~m}$ peak is in Arizona, over $500 \mathrm{~km}$ away 
and that day, Dave was complaining about the Cerro Grande fire that at the time was devastating the city of Los Alamos and its surrounding area. Fine-grained particles of ash were everywhere.

It wasn't very promising for the following stargazing party, but one was about to happen at his house. Indeed, many a Saturday near the new moon, children and adults alike found their way to the Stagecoach Observatory, an amateur astronomer's dream that Dave designed and built on his property. Two telescopes-a small one for sighting brighter objects, and the 16-inch Meade motorized,computer controlled telescope, for looking at galaxies and other remote objects. Once, at his house on Garcia street, Dave had produced two pairs of Bushnell's binoculars, to help us sight the Andromeda galaxy. But with his Meade telescope, Dave could follow the recession of Barnard's star (a relatively "close" object, only 6-light years away) —a star in the Ophiuchus constellation that intrigued ancient astronomers as it kept moving among other (seemingly fixed) stars.

The tale of two binoculars, and two telescopes, all belonging to Dave, the amateur astronomer, is a living memory that Dave never did anything halfheartedly. Indeed, Dave excelled in just about everything he set his mind to accomplish. An accomplished banjo- and guitar-playing musician, Dave developed a strong interest in acoustics and developed a new binaural recording system, because he found out that humans perceive sound as coming to the ear through the head, not just from the outside. He had his own music recording studio, complete with Argon-filled soundproof double-pane windows. A licensed pilot, he owned three aircraft, among which, a decommissioned Royal Airforce Jet Provost MK5A double-seat jet fighter, and a P68-TC Observer, a six-seats turbocharged Partenavia aircraft used for landscape survey.

A licensed chef, he built a kitchen-sink inside a grand piano, because "everything happens around the kitchen"; he calculated the harmonics of the piano to figure out where to place the pipes. Next to the piano? A T-1 high-speed internet port, because "you never know when you need access to the web". He was proud of his two-seater Chevy electric truck (he converted all his cars to electric engines), and he developed nine arrays of 16 solar panels (his "nine muses"), which generate $100 \mathrm{MW} / \mathrm{year}$ - which qualified his muses as a commercial power plant. Not one to do things halfway, Dave had studied everything about the tax incentives, selling excess electricity to the grid, and trading carbonoffsets on the international market. After acquiring a surplus mass spectrometer from Los Alamos National Laboratory, he figured out how to decaffeinate chocolate, playing with multiple extraction methods until he developed "caffeinefree chocolate"- technology that he later sold to Cadbury.

Above all, he was a true visionary and pioneer in the field of chemical informatics. From a fast and efficient way to store and query chemical structures (the linear notation language for chemical structures, SMILES and its associated substructure query language, SMARTS) to chemical-centric databases, Dave envisioned a new role for informatics in chemistry before cheminformatics was a concept. With Albert Leo, Dave wrote the first program that calculated LogPoct from structures in the late 1980s (known today as CLogP), as part of the Pomona College Medchem Project. In 1987, he started Daylight Chemical Information Systems with Josef Taitz. This company defined cheminformatics for two decades. Together with Jeff Blaney, Scott Dixon, Roger Sayle and Josef Taitz, he started Metaphorics in 1997, where he annotated stoichiometrically correct biochemical pathways before these became freely available on the web, and genetic algorithms to search for new chemical structures. While at Metaphorics, Dave learned Pinyin and about 3000 Chinese characters, in order to annotate chemical structures of Traditional Chinese Medicines. With Yvonne Martin and John van Drie (then at Abbott), Dave developed one of the first pharmacophore search programs (ALADDIN).

At multiple levels, and in many ways, Dave thought differently. After his 1993 Molecular Evolution talk at the Gordon Conference in QSAR, I made my way to Santa $\mathrm{Fe}$, and informally applied for a job at Daylight. At the time, my experience was with 3D-QSAR methods. "I don't believe you need three dimensions to describe molecules", he said as we were hiking in the Aspen Vista park outside Santa Fe. "Tell you what. Instead of coming to work for me, I'd rather we stay friends. Friendship lasts longer than employment." He went on to hire Jack Delaney from Kodak instead. Indeed, I enjoyed many Daylight MUGs and stargazing parties, and learned a lot from Dave. His fiery passion, the way he totally immersed himself into a problem, his computer wizardry and his way of changing the world ("who needs publications? If it's important, it will get out by word of mouth") have left a profound impression. It's no coincidence he bought a house that once belonged to Roger Zelazny. His love of science fiction also led him to invite Doug Adams to give a Daylight talk in Santa Fe (1998).

I can think of a no better way to say good-bye: So long, and thanks for all the SMILES.

Further reading.

https://www.wired.com/2000/06/infomesa/ and the book, The Info Mesa, by Edward Regis (ISBN 9,780,393,021,233).

http://blogs.sciencemag.org/pipeline/archives/2016/11/14/ david-weininger-and-chemical-names.

http://blog.eyesopen.com/ant/2016/11/10/dave-weiningers -passing/. 


\section{Dave Weininger: The director}

\section{Johann Gasteiger}

The first time that I met Dave was at a symposium in Durham. I sneaked out of one of the presentations, as did Dave, and then we were sitting in front of Durham cathedral-for me, the most beautiful cathedral in the U.K.- and were discussing cheminformatics and its future development. Then, as for most of us, the booth of Daylight at ACS meetings was a place to meet Dave. There he was sitting on a sofa, an island of calmness in a sea of hectic commercialization and ego-trips, receiving people to sit down and talk with him. I had visited him in Santa Fe several times but the most memorable was in March 2005.

I was flying with Dave after the ACS meeting in San Diego with his Partenavia Observer airplane to Santa Fe. The front of this airplane was all windows, you felt directly sitting in the air having an unimpeded view in all directions. After a stop-over at Flagstaff for refueling we crossed the Painted Desert. This was certainly a view I will never forget. Extinct volcanoes, red, brown, black and violet rocks-such must be a Martian landscape. I stayed for one week with Dave in Santa Fe to produce a video. Dave had the idea of producing videos of all persons that have left a mark on cheminformatics. The topic of my video was: "Computer Representation of Chemical Structures". Each night I wrote a script under the guidance of Dave until way after midnight. During the day we took the scenes in his professionally equipped video studio in the Daylight offices. I even went to the huge sculpture of the Cognition Enhancer in front of the Daylight offices and explained molecular structures and how to represent them. We really worked hard but it was a lot of fun. Dave was the director and I really did what he wanted me to do-unusually for me to submit to somebody else's wishes. But that was Dave: he was so rigorous and convincing that you could not escape. After one week we had all the scenes taken for the complete video. However, the video was never produced! I never asked Dave why not, but I guess he was too disappointed that the first video produced with Klaus Gubernator on Combinatorial Chemistry had to be destroyed on request by his former employer. I am not disappointed that our video never appeared. The collaboration with Dave was worth it. The way is the goal! (Confucius).

Thank you Dave for everything.

\section{Dave Weininger, one of a kind}

\section{Yvonne Martin}

Many will know that Dave Weininger invented SMILES and SMARTS, but not everyone appreciates his creativity, kindness, and zest for life. I was privileged know him for thirty or so years and hence to be able to spend time with him discussing both software and life.

\section{My early involvement with Dave's software}

I met Dave at an EPA meeting when he was part of the Pomona College Medicinal Chemistry Project starting in 1983. Previously, while at the EPA Duluth station (19781982), he had invented SMILES, the first line notation for chemical structures easily readable by both machines and humans. By the time that I met him he also had developed THOR, a database system to store the various properties of molecules. His poster at the EPA meeting described the organization of the MedChem THOR database: A SMILES anchored each entry with the $\log P$ and $\mathrm{p} K_{\mathrm{a}}$ values with their literature citations organized hierarchically under the SMILES. THOR was designed with the scientist in mind in that no special computer expertise was needed to use the program. By this time Dave had also developed a scheme to translate any input SMILES into a unique SMILES and formalized the SMARTS substructure identification language. Both SMILES and SMARTS were innovative in that they were easily understood by chemists but also had strong computer science behind the implementation.

When I met Dave I was frustrated trying to organize the various conformers and superpositions of molecules and also to store the relationship between the structures and biological properties of the compounds from various projects. It seemed that THOR could store my 3D data, so I invited Dave to visit to discuss the possibilities. He looked over my files and wrote a program to convert our graphics files into a tdt (THOR data tree) for loading into THOR. He elected to store the atomic coordinates in the order of the atoms in the unique SMILES string, hydrogens last (1). His insight into the importance of this mapping between the position of the atom in the $2 \mathrm{D}$ structure and its $3 \mathrm{D}$ coordinates made it straightforward for us to develop new methodologies.

Our 3D modeling efforts focused on identifying the common pharmacophore within a set of molecules. However, once we did identify a pharmacophore, we were hindered because we had no a simple way to suggest new cores on which to place the pharmacophore atoms or to find existing molecules that might contain the 
pharmacophore. With THOR in place, I contracted with John van Drie to program one of the first 3D searching programs, Aladdin (2). By then, although forgotten by most, Dave and his brother Arthur also invented Genie, a language that performed operations based on a SMARTS. Genie was key to the identification of the atoms that should be considered in a 3D search target.

After Aladdin Dave continued to consult on the integration of the MedChem software into our molecular graphics system. At the time our research informatics was making plans to move from its fragment-based database for structures to the MACCS system. The problem was that there were no connection tables for the structures. One approach to generating connection tables would have each medicinal chemist draw 1000 structures and proofread 2000 structures drawn by colleagues. In hearing about this, Dave suggested that he could convert our line-printer approximations of structures to a 2D structure for storage by MACCS. We came up with a very inexpensive contract and, although the first try wasn't 100 percent correct, when Dave then compared the database molecular formula with that generated from the SMILES, the problem structures were easily identified for a human to correct.

Dave was also busy at Pomona, specifically converting into the ground-breaking program CLOGP Al Leo's expertise on the effect of substructures on octanol-water $\log P$. Many pharmaceutical companies and research institutions were also enthusiastic users of the MedChem software: The 1980s MUG (MedChem User Group) meetings were attended by $40-50$ people. Even though it was modestly priced, by 1988 the MedChem software was so profitable that the trustees of Pomona College provided money for Dave to start Daylight and for Corwin Hansch and Al Leo to start Biobyte. A total re-write of the software in more modern computer science methods was the first order of business for Daylight. Somewhat later the ties to Oracle were developed.

Dave always maintained that the 2D structure of a molecule contains all of the information about that molecule and that it wasn't important to consider the 3D structures of molecules. Hence, I was very touched when, at the MUG meeting with Douglas Adams as the featured speaker, Dave presented me with a signed copy of "Hitcher's Guide to the Galaxy" in recognition of my realization of the need for 3D database searching of structures.

\section{Evolution of Dave's involvement in cheminformatics}

As I became friends with Dave I enjoyed asking him about how various things came to be. Much of this came from a conversation on an hours-long train ride from Newcastle to Edinburgh and back. As I understand it, he was an undergraduate at the University of Rochester, first as a student at
Eastman School of Music, but ultimately as chemistry major. After graduation he worked at a GE electricity generation plant in Canada and there became interested in water management. He enrolled in the College of Engineering at the University of Wisconsin at Madison to further study water. Part of his Ph. D. project was to collect lake trout in the great lakes and measure the PCB levels in these samples (3). After a few voyages to collect samples, Dave realized that in order to answer the question posed for his Ph. D., he would have to use all the lake trout in Lake Michigan. So, in true Dave fashion, he developed a model, which was considered "ground-breaking in the developing field of bioaccumulation of organic chemicals in the environment" (4). Because of this model, the EPA hired him in 1978 to work at their Duluth station.

It was at Duluth that Dave developed a database to record the structure-activity information that the group was generating. Operators drew the chemical structures on a GT-40 for entry into the database. As he told me, one day Dave noticed that the operators were typing rather than drawing the structures: They had decoded how the structures were stored in the computer. That night Dave went home and invented SMILES to make it easier for the operators to enter structures. The name SMILES comes from the smiles on the faces of the operators when he showed it to them. As I said above, Dave built tools for people to use to get their work done, certainly not to impress others with his brilliance, nor to amuse himself. He had no interest in publishing the details of the SMILES language: However, when his father retired from GE and the sectional editorship of Journal of the Electrochemical Society, he convinced Dave that this should be published (5). This appeared in 1988, several years after the language was invented.

\section{Dave's zest for life}

Many people know that Dave was an enthusiastic pilot. But did you know that he had a dream to take the governor of New Mexico on flights to visit every airport in the state? His hope was that the governor would then have a deeper understanding of the circumstances of the people in the state. Many also know about the statue that he designed for outside the Daylight offices. But did you know that he often visited the Shidoni Foundry and Gallery in Santa Fe? Many know that he developed a method to separate the caffeine and related compounds from chocolate. But did you also know that he and his brother Arthur spent a summer perfecting a bagel recipe so that they could have that taste of New York while living in New Orleans? Or that he bought an orange juice machine at a Navy surplus auction and fed it with oranges for the Daylight crew?

Dave was famous for his star parties. They arose from neighbors' objections to the white building that he bought 
to house his telescopes. To start to mitigate this complaint Dave painted it the color of the soil around the building so that it would recede into the landscape. He then decided to turn the observatory into a neighborhood asset by holding a monthly open observatory to which he invited his neighbors (and their grandchildren) to view the skies. Thus Dave turned a neighborhood feud into a neighborhood festivity.

Dave was a unique person whom it was a special honor to know. He was one of a kind.

(1) Martin, Y. C.; Danaher, E. B.; May, C. S.; Weininger, D. MENTHOR, A Database System for Three-Dimensional Structures and Associated Data Searchable by Substructure Alone or Combined with Geometric Properties. J. Comput.-Aided Mol. Des. 1988, 2, 15-29.

(2) Van Drie, J. H.; Weininger, D.; Martin, Y. C. ALADDIN: An Integrated Tool for Computer-Assisted Molecular Design and Pharmacophore Recognition from Geometric, Steric, and Substructure Searching of Three-Dimensional Molecular Structures. J. Comput.Aided Mol. Des. 1989, 3, 225-251.

(3) Weininger, David; Accumulation of PCBs by Lake Trout in Lake Michigan. Ph.D. Thesis University of Wisconsin, 1978.

(4) https://www.engr.wisc.edu/2003-distinguished-servi ce-award-david-weininger/

(5) Weininger, D. SMILES, a Chemical Language and Information System. 1. Introduction to Methodology and Encoding Rules. J. Chem. Inf. Comput. Sci. 1988, $28,31-36$.

\section{The wit, wisdom and Wonder of Dave Weininger}

\section{Anthony Nicholls}

Dave Weininger never had much time for communities, other than those freewheeling ones he created for himself. And yet, or perhaps because of this, he had more impact in the field of chemical informatics than anyone since, well, Kekulé. If that sounds like hyperbole consider this: In 1975, in his classic book, "The Periodic Table", Primo Levi, chemist, Auschwitz survivor and probably the best science writer of his generation, lamented that there were only three ways to name a molecule: its chemical formula, which was lacking any sense of atomic connectivity, a common name whose origin was either obscure or hard to decipher, and that molecule's depiction, which was a poor substitute for a language. He died shortly before SMILES was invented by Dave but sometimes I like to imagine what a meeting between the two of them would have been like: the Italian, Jewish polymath and the American,
Jewish polymath, entertaining and entrancing each other, ending with Dave drawing chemical structures and writing their simple, elegant SMILES strings on some napkin that Primo then tucks into a pocket. It would have been one for the history books because Dave did make history, not just with SMILES but with canonicalization, SMARTS, Daylight fingerprints, his insights into the importance of databases rather than file formats, and so on. But it will be SMILES that ought to put him in the history books. He deserves to be; he's the only person I've ever met who really was touched by genius, someone whose name might be known a hundred or three hundred years from now.

I'm not going to attempt to tell the story of SMILES, Daylight or even Dave; I expect there are others who will do that, including, apparently, a film effort in his latter days. But I would like to share some of my memories, in particular the advice he freely dispensed, sometimes crazy and sometimes life changing. When I heard the sad news that he would not be with us for much longer it forced me to write down those aphorisms and I was really shocked as to how many there were, and how influential some of them have been, especially in shaping my company, OpenEye.

The most important one, in fact one of the principal reasons there even is an OpenEye, came as he and I were driving to Socorro, about two hours south of Santa Fe, for no other reason than to visit a roadside diner. I'd been in Santa Fe just a couple of months since my "Escape from New York" at the end of 1995 and Dave was allowing me to crash at Daylight for a few weeks. He turned to me and said, out of the blue, "You know, if you really believe in something, really believe, then you have an enormous advantage over most people, because most people don't really know what they believe. It's such a huge advantage that you almost can't fail. However, you don't get to control the time scale of that success." Of course, I did totally believe in shape and electrostatics as a way of capturing molecular identity and it was and continues to be an enormous advantage. And I was successful, and it did feel inevitable. And I am suitably shocked that that was twenty years ago! Right on all counts.

I keenly observed what Dave had done at Daylight, and really OpenEye was an attempt at reproducing that business meme but without someone with his charisma or genius. I liked that Daylight was liked, I liked the idea of toolkits to empower people, I liked that everyone had offices but had lunch together, I liked the idea that you didn't have to take investment money from anyone: you could survive and thrive by just making things. Here's a collection of his comments that influenced the formative years of OpenEye:

(1) "The idea is that you plant your flag in the ground and see who rallies round. Someone always does and they become your friends and colleagues." 
(2) "Never sell anything to someone who doesn't need it. Yes, you get their money but you won't get their repeat business and that's what you really want"

(3) "It's not complicated: You make something for someone and if they like it they come back and next time do a bigger deal".

(4) "If you want to live and work outside the 'system', then you have to live on your wits. But that's ok"

(5) "Santa Fe's a place that's always rewarded creativity, in whatever form. People think of it in terms of art and so on, but why not programming?"

(6) "Licensing schemes are just there to keep the honest people honest; there will always be some bad actors, that's just life, but don't stay up late worrying about them"

(7) "People always say to me, 'Dave, Daylight's great, you could be the next MDL', but then I tell them, 'Have you looked at MDL? Do they look like they're having any fun? Why would I want to be them?"

(8) "There's this idea that to be successful you have to grow and grow and that's what success means: growing. But I like the idea of 'right-size', that there's a right size to any company and you just have to find it and stop there"

(9) "If you are in business why write grants? They take a lot of time, time you could be spending writing code, you don't know if you're going to get them and by the time you do you probably want to be doing something else!"

(10) "Don't get into a pissing match with a skunk"

(11) "It's better people underestimate you" (Thanks to Jeff Blaney for this one)

(12) "Don't worry if people don't buy something. I always feel they can buy now or they can pay more later!"

That's basically how and why OpenEye became OpenEye. We never took investment, never wrote grants, didn't obsess about licensing schemes, don't pressure people to buy something they don't need, and we're still trying to find our "right size".

There were other, more technical things I learned: the idea of a constant API that you stand behind for always, i.e. requiring you to think deeply about design so as to get it right. The idea of the API hiding the implementation so that you can change that at a later time. The idea of a molecular description not as a file format but as something more formal; he always referred to SMILES as a "language". I always wanted that for 3D shape-still working on it!

Some of the things I remember aren't work related but made me laugh, or laugh and think. Dave always thought one of the best jobs you could have was as a florist- "Everyone loves flowers so who's ever not happy to see you?". He didn't see how anyone could be a dentist! Another: "Airports are essentially happy places; everyone's on the move to go to see someone they care about or to be a place they want to be." Apparently Dave sometimes missed connecting flights because he would become so engrossed watching people! He loved movies and had a great entertainment system. One of the things he liked to do was to synchronize the food being eaten in the movie with you actually consuming that food, e.g., if it's "Bladerunner" you better have some cheap noodles ready. Try it!

There were bigger life-work observations. One of the most profound and, given the move to open offices, currently relevant is his philosophy on work environments. As Dave put it, "You know most people think you go to work to, well, work and you come home or go to some quiet spot to think. I think that's completely backwards. We come together to think, we go away to work.". It took me a while to really get the depth of this and only then because I was lucky enough to have collaborated with Andrew Grant in the UK. I used to travel there regularly and Andy was always keen we sit down and write code. I was naturally a bit jet-lagged (7 h!) and would protest that it was sitting around talking that I really appreciated. It was one of the few really contentious arguments he and I ever had and yet one day, years later, he came to me and admitted he now saw the light. Those conversations with him and with others in that great group of modelers Dave Leahy had put together were immensely functional: we really did 'think' together. There was always time, later, for writing code. Come together to think, go away (even if just to an office) to work. Of course, Dave would go to some Caribbean island to 'work'!

Another concept he'd observed that I've increasingly come to see the truth of is the concept of "self-permission". His view was that sometimes people want you to give them permission to do something they really don't have to ask about. As he reminded me, "For instance, you asked me permission to leave Columbia and come out to Santa $\mathrm{Fe}$ and do your thing. You didn't have to ask but you felt you should ask". I've observed this since and it's helped me not be dismissive ("Why are you even asking?!") but to try and be as graceful as Dave always was with such requests.

Dave really achieved things, he finished projects. He was an exemplar of the Steve Jobs' aphorism that "real artists ship". He always referred to that phase of pushing something through to completion as "leaning" on something. "Sometimes you've just got to 'lean' on something, you know?". Of course, Dave was a big guy so it was an easy image to get. Also he tended to work in ridiculously long jags of time, something I've never been able to do.

The last "deep thought" he shared with me came in the parking lot of the original Daylight building in Santa Fe: an ex-home to unwed mothers with all that great karma- and the place I initially bunked when I came to town. He said, "You know people always worry about the future, where they'll be 
in five or ten years. I don't know why they do that because how do they even know who they will be by then? I'm not the same person I was five or ten years ago and I don't expect I'll be the same person in five or ten years time". I often think of this in the context of how Dave essentially abandoned cheminformatics. I think he had done all he wanted to, but more than that, he'd just become a different person.

I also think a throwaway joke of his, wherein he used to paraphrase Newton with, "If I can't see very far it's because I've giants standing on my shoulders", wasn't entirely a joke. When you start something you have all the time in the world (or so it seems) and you can see so far. Then, as time goes by, you get pulled in so many directions, accrete responsibilities and duties that you really don't get to look up as much, and when you do it's hard to see further than the next meeting or the next deadline. I don't think Dave enjoyed that much and I don't think he wanted to be some senior, respected, legend of the field.

Last two, predictably enough on death itself. I remember him announcing as axiomatic, "You know life is intrinsically unfair because at the end you die: what's fair about that?". The other has taken me much longer to appreciate, "The one thing that really sucks about getting old is not dying, it's having your friends die before you". At the time I hadn't had many close friends die so I didn't really agree with him- I mean, couldn't you just get new, younger friends (like me)? Now, years later, I realize what he meant; how the death of a friend is like a piece of you disappearing that you never get back. So it goes with the passing of Dave Weininger.

They were magic times, those early days in Santa Fe. His fighter jet, him bringing Douglas Adams to a MUG meeting (he'd met him years before on a yacht vacation and had stolen his towel!), MUG meetings, the Daylight ACS booth, trips to Downtown Subscription (a coffee shop that was neither), Horseman's Haven, the star parties, his world's-best blackberry pies, the orange crushing machine, the molecular statue at the new Daylight building, the way he was always happy to receive a guest and dissect the world from a new and interesting angle. He was once described as someone who could walk into a room full of people he didn't know with the confidence that only comes from assuming everyone would love him, and they usually did. He wasn't perfect, that's for sure, but he was a remarkable man, one who lives on in many of our lives, our work and our businesses.

I once thanked him for all the help he'd given me. He looked at me quizzically, and asked, "What help?". When I went down the list he listened and then just shrugged, smiled his big smile and said, "Well, pass it on". 